\title{
On the Cultivation of Automation Majors' Research Innovation Ability Based on Scientific Research Projects
}

\author{
Lipeng Wang ${ }^{1} \&$ Mingqiu $\mathrm{Li}^{1}$ \\ ${ }^{1}$ College of Electronic Information Engineering, Changchun University of Science and Technology, Changchun, \\ China \\ Correspondence: Lipeng Wang, College of Electronic Information Engineering, Changchun University of \\ Science and Technology, Changchun 130022, China. Tel: 86-138-0431-8749. E-mail:wanglipeng12@126.com
}

\author{
Received: February 3, 2012 Accepted: September 13, 2012 Online Published: November 28, 2012 \\ doi:10.5539/hes.v2n4p137 URL: http://dx.doi.org/10.5539/hes.v2n4p137
}

\begin{abstract}
Currently, it has become a fundamental goal for the engineering major to cultivate high-quality engineering technicians with innovation ability in scientific research which is an important academic ability necessary for them. This paper mainly explores the development of comprehensive and designing experiments in automation based on scientific research projects and elaborates on the significance and indispensable role of these experiments in cultivating students' research innovation ability.
\end{abstract}

Keywords: scientific research project, comprehensive and designing experiments, research innovation ability

\section{Introduction}

In the educational field, it is comparatively late for our country to know for cultivating students' research innovation ability. Our country has advocated cultivating innovation talents based on the reform of higher education from 1980. And the research innovation ability of post graduates is first to be intensified. However, with the strengthening reform and investigation of world's advanced universities, a group of research universities, such as Qinghua university, Beijing university, Zhejiang university, Nanjing university and university of science and technology of China, begin to bring scientific research topics into undergraduates' education, taking scientific research as important measures to cultivate students' research innovation ability. Though it is influenced by the factors of inherent education pattern, the weak results of research and innovation, the imperfect measures and some inevitable problems, our country's universities still have some wonderful achievements on the aspect of cultivating students' research innovation ability. And some excellent universities have accumulated much beneficial experience during exploring and trying. From 1996 up to now, Qinghua university has been establishing a comparatively perfect supporting program of students' extracurricular academic research project step by step, mainly including the student research training platform, the innovation platform of practice and investigation, challenging cup special project. University of science and technology Beijing takes innovation plus practice pattern, on campus, based on the different needs of science and engineering students, it specially sets up two university-level undergraduate innovation foundations which are named as student natural experiment center and engineering training center, and five college-level undergraduate innovation institutions named as civil engineering, metallurgy, material, machinery, and information, outside the campus, it invests ten million Yuan and cooperates with more than one hundred big and medium size enterprises and public institutions, local authorities and governments for continuous four years to set up 145 practice foundations, covering entirely 44 bachelor's degree program of the whole university. (Zhou, 2011)

In the 21 st century, higher education is characterized by creative, innovative and carve-out education. At present, when laying down their cultivation plan for the automation major, most universities include the following targets: (1) having certain abilities in scientific research, science and technology development, organization and management as well as strong adaptability in work; (2) gaining good practice in systematic analysis, design and development and grasping certain abilities in scientific research and practical work; (3) being capable of carrying out systematic analysis, design, operation, development and research in science and technology in motion control, industrial process control, power electronic technology, detection and automation instrumentation, computer control, information processing, management and decision making and so on. In the aspect of cultivation goal, automation talents are expected to have solid theoretical basis, strong professional skills and excellent research 
innovation abilities. Compared with theoretical teaching and replication experiments which cannot satisfy the pre-set goal, comprehensive and designing experiments can better stimulate students' interest and curiosity, hence helping to develop students' abilities in observation, practical operation, research innovation as well as their comprehensive quality. Therefore, it seems urgent to reform the current experiments to develop comprehensive and designing experiments reflecting the latest development and helping to cultivate students' research innovation. At present, it is a critical issue in the experiment teaching reform in universities to explore how to rely on teachers' research projects to develop comprehensive projects so as to promote teaching with the propelling power of research and to achieve an effective fusion of teaching and research (Fang, 2011).

Student research innovation ability refers to an ability shown in the process of using elementary knowledge and professional knowledge to develop research activities, using scientific approach to explore the nature and rules, with the help of certain experimental instruments and related skills, based on mastering certain basic theory and professional knowledge (Yao, 2010). Generally speaking, it includes five abilities of informing, questioning, thinking, practicing and writing. Cultivating students' research innovation ability will make them think deeper about what they have learnt, spontaneously look up related information and master the holistic approach and newest development of subjects, meanwhile, the thinking and questioning capacity of themselves, capacity of searching for information and sifting information and the quality of patience, consideration and insistence will also be improved. The discretion of student research capacities displays the level of running a school and comprehensive strength of colleges and universities, thus, most universities are exploring, learning and accumulating the methods and experience of training innovation talents and establishing research-based teaching system step by step. As the reform of our country's higher steps into a substantial phase, many patterns of talents cultivating which adapts to the needs of 21 st century are turning from experimental unit to application and dissemination. The talent pattern which takes cultivating students' research innovation ability as breakthrough is the key for educational reform and development plan of colleges and universities. They reform the teaching plan of undergraduates' course with great effort, launching multiform activities to develop qualities, setting up related incentive system and policies, and trying to create a favorable environment for research innovation one after another, based on their own subject characteristics.

\section{Principles of Developing Comprehensive and Designing Experiments}

In spite of a large number of universities' efforts in promoting teaching with research, the result is not quite satisfactory due to the improper projects they have selected. The following principles should be followed when we develop comprehensive and designing experiments relying on research projects:

\subsection{Developing Innovative Projects Reflecting the Latest Disciplinary Development}

In order to cultivate students' research innovation, comprehensive and designing experiments should be chosen related to modern automation technologies. Therefore, research projects reflecting the advanced control technologies and methods in the automation field should be based on to develop the requested experiments. Accordingly, teachers engaged in the main technology courses of automation are expected to participate in the development of experiments, to learn about the latest trends of disciplinary development and to display them in teaching. Thus, research achievements can be made use of to enrich experiment teaching, hence satisfying automation majors' demands for experiments and practice.

\subsection{Developing Projects Closely Connected with Specialty Orientation and Reflecting Specialty Features}

The automation specialty displays different features in different universities. The selected projects should reflect and strengthen specialty features as well as be closely combined to the cultivation orientation of the automation specialty.

\subsection{Developing Projects with Reasonable Difficulty and a Step-by-Step Way}

First of all, too hard projects cannot be selected since students may be frightened and frustrated by them, hence influencing their activity, enthusiasm and creativity, nor can too easy ones because such projects seems of less value for the development of comprehensive and designing experiments. Projects with reasonable difficulty can help students to learn about the latest development in the relevant field as well as to cultivate their research innovation abilities.

\subsection{Developing Feasible Projects}

Feasibility here refers to the possibility to achieve the expected goal, which requires full consideration of all the objective conditions necessary for a project. First, fund support is required to transfer an ordinary research project to a comprehensive and designing one. However, the fund for this is not sufficient in most universities. As a result, this issue has to be taken into consideration during the selection of projects. Second, the real 
laboratory conditions have to be considered as well to make projects workable (Fan, 2007).

\section{Cultivation of Students' Research Innovation with Comprehensive and Designing Experiments Relying on Research Projects}

The process of developing comprehensive and designing experiments covers the following steps: a proper project is chosen first of all and then further divided into some comprehensive and designing experiments and listed into the specialty syllabus after being approved by the specialty committee. When conducting experiments, students are divided into groups of three of four members. They begin with looking up literature, learn about relevant basic principles as well as main contents, methods and steps involved in the experiment and then list the needed facilities and instruments. After that, the teacher will check the reasonability and feasibility of students' experiment plans, pointing out and correcting problems. Based on the teacher's revision, students can start their experiment. After conducting the experiment, they will analyze and sum up the data and results they have collected in the experiment, draw the conclusions, write a report and have relevant papers published. Through such a series of practical research training, students' innovation potential can be fully exerted and their practice ability and research innovation ability can be improved as well. (Yang, 2010)

\subsection{Participating in Research Topics is Good for Helping Students Have a Clear Life Goal}

Today some students of universities have an unclear aim of learning, a wrong learning attitude and ignore school disciplines and rules and don't pay attention to professional study, and lay particular stress on social activities. For them being at school is nothing but "fish for a certificate" or "enjoy four years". It influences the study atmosphere and school spirit seriously. However, study atmosphere and school spirit building is the eternal theme of higher schools' reform and development. Without good study atmosphere and school spirit, there is no harmonious campus atmosphere. Launching research activities with great effort among students will restrain their blundering psychology and turn passive study into positive study. Sometimes students think that most theoretical knowledge is boring and it is difficult to combine theory with practice. Research activities can help students deepen the understanding of theoretical knowledge of textbook and the cognition of research objects. It helps to put theoretical knowledge into practice so that students can use it and have a better understanding of it. The activities are also good for digesting and absorbing knowledge. It makes study more directional and helps to set up one's own goal and ideal, so to realize individual values initially and boost harmonious campus building.

\subsection{Creating an Innovative Atmosphere for Research}

A vigorous academic atmosphere can endow students with a scientific spirit, from which students will have their innovation ability developed by constantly absorbing creative spirit. In the teaching process with comprehensive and designing experiments, "combining teaching with research" should be taken as the guiding idea. Students should be encouraged to write essays according to the experiment and be organized to have seminars and workshops regularly. Experts in or out of the university should be invited to give lectures to inform students of the latest information and knowledge, hence intriguing and strengthening their sense of innovation. During their experiment, in addition to their laboratory practice, they can go to teachers' research center to personally experience the atmosphere in which their teachers carry out scientific research.

\subsection{Cultivating Students' Ability in Looking up and Applying Literature}

It is an important way to cultivate research innovation ability to constantly accumulate knowledge and to absorb others' experiences and lessons through looking up reference material. Since some profound professional knowledge is involved in comprehensive and designing experiments, teachers are expected to guide students to look up Chinese and foreign literature, instruments and network information resources in the right way and to trace the latest development of their field of study.

\subsection{Encouraging Students to Have Independent and Innovative Thinking}

Difficulties are unavoidable during experiments, so students are supposed to calmly find, analyze and solve problems. In this process, teachers should give students encouragement and illumination to lead them to have independent thinking and analysis, to find, reflect on and analyze problems and to come up with a variety of solutions from different perspectives (Zhou, 2008). In addition, with teachers' instruction, students' innovation potential can be fully exerted, their innovation interest can be strengthened, their innovation inspiration can be stimulated, their acute innovative thought can be formed and therefore their innovation ability can be cultivated.

In experimental teaching process, besides the demonstration and application of theoretical knowledge, it should be learnt to guide students to solve new problems which appear in experimental process, for example, carrying out experiments according to experimental procedures which are set by experiment instructions. However, there are always some students who can't figure out the results. If the instructor requires them not to give up easily and 
go on with the experiments until the expected results are achieved, he needs to accumulate experience constantly in his regular research work. He should help students to conclude the reasons of failure after experiment success. In the process of experiment the unusual phenomena and consequences should not be denied easily or revised and stopped by established conclusions in textbooks. Instructors should lead students to think all by themselves to find the media theoretical explanation and encourage them to look up related reference data and probe into the true reason of problems. Then student abilities of active analysis and solving problems independently will be cultivated.

\subsection{Cultivating Student Scientific Attitude of Seeking Truth from Facts}

Scientific research staff must have a precise attitude and practical style of work towards science without any falsification. It is the basic premise for innovation to cultivate students' precise attitude through comprehensive and designing experiments. Only with the attitude of seeking truth from facts will some creations be made on the way of exploration. In addition to that, students should learn to be a person by forming good virtues during the studying process.

In comprehensive design experiment teaching process, every student's original data sheet should be checked and after signed, the sheet should be enclosed into the lab report. That's because in the teaching process it is found that most students formed such concepts in learning and teaching: it is right only when the experimental result matches the standard answer. If the experiment failed or the phenomenon is ambiguous, students would copy the theory or other's experimental phenomenon and conclusion passively rather than analyze the reason of failure. Once the bad habit of not being realistic is formed, it will be difficult to correct. Thus, regulations must be strict from the first experiment and a nice set of data is not equal to high mark. How to analyze every experimental result is important. And in lab exams that should be insisted. Speaking for itself, every person who works on experiment research must have the scientific attitude of respecting the truth and being realistic, especially in comprehensive design experiment, every experimental result should be analyzed according to the truth rather than some false data in order to reach the expected result. (Zhou, 2009)

\subsection{Training Student Fluent Writing Ability}

In the phase of demonstrating experiment project alternative and composing the paper, the instructor should introduce the main journal papers at home and abroad, the format, methods and techniques of graduation paper; make undergraduates initially master the basic writing methods and know the requirements of abstract, introduction, experiment or theoretical part, conclusion and bibliography, and provide students with fluent writing ability.

\subsection{Cultivating Students' Teamwork Spirit}

Developing students' teamwork spirit refers to developing their communication and coordination abilities, which is of particular importance for the communication and cooperation of a research team. In comprehensive and designing experiments, all members of a group are expected to finish different tasks in an experiment through their cooperation, such as project application, looking up literature and other materials, analyzing data, writing project reports and so on. In such a process, students can be trained and improved, learning how to arrange different tasks and finishing them through cooperation. Students will regard scientific research as a social activity as well as an academic one, which calls for not only cooperation in a group but interaction with the outside world (Wu, R., 2011; Wu, B. G., 2011).

\subsection{Giving Full Play to Instructor's Directive Function and Bringing His New Research Method and Years-accumulated Research Experience into Experiment Teaching}

A creative teacher could help students make rapid progress on the road of learning and teach them how to handle a great deal of information. He is more a guide and advisor than a simple tool for passing on knowledge mechanically. After students set up the topic initially, they can tell instructors their thoughts and ask for evaluation because instructors have more experience and know better the development trend of different research fields and problems which are in bad need to be solved. Instructors teach students in accordance of their aptitudes. Students with different aptitudes will have different guidance. The equivalence in teacher-student communication is good for training student original creation spirit and enhancing his research capacity. Instructors could bring their used new research techniques and new methods into experiment teaching and keep experiment teaching methods and approach update in the process of guiding experiment. Through developing comprehensive design experiment projects to imitate the whole research process, the organic combination of new experiment teaching and research techniques and new training methods will be achieved. (Jazlin Ebenezer, 2011)

To sum up, cultivating students' research innovation ability which is based on comprehensive design project will 
mainly provide students with opportunities of research training and make them step into professional research field as soon as possible. They can contact with subject's leading edge and have a clear idea of the subject's newest developmental trend. Training student independence, teamwork spirit, innovation spirit, innovation capacity, the ability of knowledge application and self study, and rigorous scientific attitude will make students understand the truth of study and research, capacity and innovation, working and achieving. They can master basic programs and methods of scientific research and their research capacity and comprehensive quality will be improved.

\section{Conclusion}

From the perspective of improving automation majors' research innovation ability, this paper elaborates on the principles and steps for comprehensive and designing experiments. In addition, the significance of these experiments are listed from five aspects including creating an innovative atmosphere, improving students' ability in looking up and applying reference materials, encouraging students' independent thinking, cultivating students' innovative thinking, developing students' precise attitudes to science and their teamwork spirit.

\section{References}

Ebenezer, J., Kaya, O. N., \& Ebenezer, D. L. (2011). Engaging students in environmental research projects: Perceptions of fluency with innovative technologies and levels of scientific inquiry abilities. Journal of Research in Science Teaching, 48(1), 94-116. http://dx.doi.org/10.1002/tea.20387

Fan, S. Q. (2007). Strengthening College Students' Research Practice and Cultivating Innovative Talents. Coal Economic Research, 1, 75-76.

Fang, Z. B., \& Xu, X. R. (2011). On Improving College Students' Research Innovation Ability. China Electric Power Education, 17, 35-37.

Wu, B. G., Zhang, J., \& Gao, C. C. (2011). Research on the Knowledge Innovation Abilities of University Science Parks Based on GEM Model. Advanced Materials Research, 228, 749-754. http://dx.doi.org/10.4028/www.scientific.net/AMR.228-229.749

$\mathrm{Wu}, \mathrm{R}$. (2011). Innovative Physics Experiment and Student Culturing of Innovation Ability. $R$ Laboratory Research and Exploration, 30(7), 79-81.

Yang, W. (2010). A Research on Cultivating College Students' Research Innovation Relying on Technology Competitions and Innovative Experiment Plans. Ideological and Political Research, 26(6), 114-116.

Yao, W. X., \& Teng, Z. S. (2010). Practice and Reflection on the Cultivation of College Students' Innovation with Innovative Experiments. Journal of Higher Education Research, 33, 94-96.

Zhou, L. M., \& Song, C. W. (2011). Cultivating Undergraduates' Research Innovation in Choosing a Subject for Research. Journal of Heilongjiang Educational College, 30, 30-39.

Zhou, W. F. (2008). Conducting Teaching through Comprehensive and Designing Experiments with a Research Pattern. Laboratory Research and Exploration, 27(2), 92-95.

Zhou, W. F. (2009). Reform of Experimental Teaching Mode and Cultivation of Innovative Talents. Laboratory Research and Exploration, 28(7), 116-118. 